\title{
Effective Mind Maps in E-learning
}

\author{
Petr Kedaj ${ }^{1}$, Josef Pavlíček ${ }^{1}$, Petr Hanzlík ${ }^{1}$ \\ ${ }^{1}$ Department of Information Engineering, \\ Faculty of Economics and Management, Czech University of Life Sciences, Prague \\ Kamýcká 9, 16521 Prague 3 - Suchdol \\ kedaj@pef.czu.cz
}

\begin{abstract}
This article presents the role of mind maps in creating well-structured elearning materials and courses, which has become very important with increasing influence of new technologies and alternative study modes. The basic principles of mind mapping are described, including structural components of mind maps, and examples of practical use cases. Based on the identified lack of existing methodical frameworks for creating interactive mind maps for e-learning, we present a set of rules and metrics, which can help to identify points of ineffectiveness, and eliminate redundancies. This framework for creating effective mind maps and its implications are described in details with help of illustrative figures and textual description. The maps that has been created in accordance with this methodology are clear and comprehensible.
\end{abstract}

Keywords: Mind Maps, E-learning, Education. 


\section{Introduction}

The educational efforts have always faced the challenge to teach the target group of students a specific set of knowledge in a fast and effective ways. This challenge can nowadays be approached in a more directed and flexible way, thanks to the advanced ICT technology. This technology can simplify the work of pedagogues, especially in combination with wellstructured educational materials support the targeted dissemination of knowledge. In certain cases, the modern information systems are designed to fully replace the human lecturer. Such systems have been occurring mainly in relationship with e-learning, and its increasing influence on college and university education. This tendency is very pronounced in case of study programs organized in combined and distance study mode, because of the possible lack of direct interaction with pedagogues. The study materials intended for courses organized in this way must thus be well-structured and clear.

In order to design e-learning courses for this specific educational need, mind maps can be used as a tool and method for structuring study materials. The big advantage of this approach is the intuitive visual representation of knowledge, which supports the education process education (Jamieson, 2012). The validity of this presumption has been proven by various practical use cases in education. According to Mey, Kun, and Hai (2010), mind maps have been successfully implemented at the Beijing Normal University at Zhuhai as a tool for creating interactive dictionaries. Thanks to the general properties of a map maps, it is possible to connect the key idea (word) with other concepts based on meaning, problem domain, or pronunciation similarity, which is a desirable property for teaching foreign languages.

Even though the mind maps can be a very useful tool for creating study materials, there are currently no guidelines for using it in effective and comprehensible way. Theoretically, a mind map can be of unlimited size, which can scatter the problem domain into individual words rather than create its descriptive and understandable representation. A tool intended for simplification can thus become a source of confusion. We have observed this phenomenon in direct cooperation with students. In order to solve this problem, we have designed a set of simple metrics and structural limitations for creating mind maps, which should ensure the necessary level of clarity and comprehensibility required to distribute knowledge effectively in e-learning courses.

\section{Materials and methods}

\section{$2.1 \quad$ E-learning}

Many definitions of E-learning have been proposed in relationship with dynamic development of this field in recent years. According to Wagner (2005) is E-learning an "educational process, which uses information and communication technologies to create courses, distribute study materials, direct communication between students and pedagogues, and to administer and manage study groups". Zounek (2009) describes E-learning as "theory and research, as well as any educational process (with varying level of intentionality), conforming to principles of information and communication technology that works with electronic data". The actual use case of ICT and availability of study materials primarily depends on intended educational goals, on contents and characteristics of study courses, but also on the environment and possibilities of all the participant of educational process.

The most important aspect of relationship between e-learning and ICT is described by Zounek, who says: "Education does not exist for technologies, but technologies are here for education." 
(Zounek, 2009, s. 49). Until recently, the e-learning has primarily been focused on personal computers. However, the rapid development of mobile devices combined with general availability of mobile internet has significantly broadened the impact of electronic education. The interactive courses are now available everywhere, because users generally carry their devices with them. In case of e-learning courses for mobile phones, the term mobile learning (m-learning) is currently preferred, to emphasize the impact of these technologies on education.

\subsection{Mind mapping}

Mind mapping, which was introduced by the English scholar Tony Buzan, is a method used to generate, visualize, structure, and classify ideas in order to help human memorize. A mind map is a diagram containing key words and pictures. (Grabowik, Knosala, 2003) It can show relationships between all key words at all levels clearly, and it can build the memory link from key words to pictures and colours. It utilizes both left and right hemisphere of brain, and can thus be used as a memory-aiding tool. Elements of a mind map are arranged intuitively, according to the importance of concepts, and marked by different colours and pictures. Elements are classified into groups, branches, or areas to represent semantics and other connections between portions of information. (Zhang et al., 2010) Mind maps may also aid in recalling existing memories. Such applications however still have some shortcomings. First, each mind map is individual, and it can only show what has been drawn on it. Represent any relationship among knots placed in different mind maps is thus difficult. Therefore, ones' memory is cut in small pieces. Second, when users create mind maps, the computer cannot provide any information about the current keyword, even whether it has been used before. Third, the method of reviewing existing mind map systems is limited to 2D. (Chien \& Buehrer, 2008) An improved mind mapping system will be introduced in the following part.

\section{The mind maps are composed of:}

- Central idea: In the classical concept of mind mapping, the central idea can be represented in two different ways. The first one relies on placing the idea into a central image, which forms umbrella term for the whole issue. (Buzan \& Griffiths, 2011) The second formulates the central idea as a short textual expression, typically the name of the issues studied. (Polivaev, 2008) In both these scenarios of central idea representation, the accuracy and simplicity is crucially important.

- Keywords (Edges): In mind mapping systems, important contents are expressed by keywords. In traditional memory mapping methods, these key words hide among many comparatively unimportant words, which hamper the brain from getting the associations between keywords. (Buzan, 2005) When keywords are used, they force humans to think about what kind of relation is between them, which helps in systematic and rapid integration of knowledge.

- Nodes: The mind map nodes represent the points, where the key words (represented by the map edges) meet. (Budd, 2004) The primary node of every mind map is a central idea. The nodes are connected through the edges, and each node is connected either directly or indirectly with the central idea. (Černý, 2014a)

\subsubsection{Examples of the use of mind maps for study purposes:}

- Brainstorming: is one of the key techniques of creative thinking. It is traditionally connected with group approach to problem solving. However, this technique can be 
used by a single person too, though in a lesser scope. The obvious application fields are the multi-solution, and often nondeterministic problems, such as finding the optimal solution or feasible alternatives.( Černý, 2014b)

- Visualisation: many students at arbitrarily level of education find it difficult to imagine what they have neither seen nor experienced before. The younger the student, the more demanding and time-consuming such task becomes. With the help of a mind map, even highly complex scenarios, such as historical context, the relationship between ideas and concepts, and their hierarchies can be outlined in a clear and conclusive way.

- Decision-making: the process of decision-making is often complicated for students. This is a typical example of ability that is not inborn, but acquired throughout the lifetime. A mind map can simplify these processes by illustrating the influential factors for a problem under review. Mind maps are thus often utilized in management as an extension to SWOT analysis.

- Time and project management: mind maps can also serve as an original task list, or a project management suite. When creating a plan in this way, students learn to think about time, realize the need to plan it, and reckon with its limited supply. By mapping the individual tasks, they acquire an experience about how much time individual activities take, and make it available for further reference.

\section{Results and discussion}

\subsection{Effective mind maps}

We decided to develop a methodology for designing effective mind maps. Effective mind maps are such mind maps, which eliminate redundant information. There are several sources of redundancy, among which the prominent place take:

- Cyclical knowledge (human can reach a conclusion in many different ways)

- Loss of a key term

- Time induced redundancy, connected with the forgetting factor

- Map complexity induced

Effective maps are hence such, which are easy to understand and perceive, thus such without redundancies.

\subsubsection{Clarity of mind maps}

The clarity of mind maps is given by several factors - the number of nested nodes, the number of leaves connected to a single node, the number of redundant nodes, and several others. Our empirical research suggests the number of child nodes of the central idea should not be greater than 7 (nesting depth). The same rule applies for the leaves (nodes with no descendants) on one level, too. Any map that fulfils these rules can be called effective. We present the matrices that can be used to assess the effectiveness of maps numerically in the consequent chapter 3.1.3.

The structure of a map in connection with the context is another factor of clarity. Each branch of the node corresponds to an analyzed context. The context is expressed more specifically with increasing depth of nesting. 


\subsubsection{The factor of time in creating mind maps}

Time is one of the most important variables that have influence on creation of maps. We have experimentally found out that a daily opened map expresses a stronger information power than a map opened once a week. If we then assume a mind map, which has not been used for longer than a month, the possible usefulness for a general user is practically negligible. Certain group of users save the individual maps and create a contextual list intuitively. In such a case, it can be said their mind maps are completely effective. The reason for this is the natural selection and structuring of mind maps, which the author necessarily follows. Otherwise, such a structure can quickly lose the organisational paradigm, and become inapplicable. 


\subsubsection{How to design an effective mind map}

We propose several measures of mind map effectiveness

\begin{tabular}{|c|c|c|}
\hline $\begin{array}{l}\text { Effectiveness } \\
\text { points }\end{array}$ & Effectiveness function & Effectiveness description \\
\hline Node points & $\mathrm{np}=(\mathrm{x}) / 7$ where $\mathrm{x}=$ number of children & $\begin{array}{c}\text { Each node should have number of children } \\
\text { in interval }<0,7>\text {. If it has more than } 7 \text {, } \\
\text { effectiveness is decreasing. Metrics says } \\
\text { that if final number is bigger than } 1 \text {, } \\
\text { effectiveness is low. }\end{array}$ \\
\hline Root wide points & $\begin{array}{l}\mathrm{rwp}=(\mathrm{x}) / 7 \text { where } \mathrm{x}=\text { number of nodes } \\
\text { joining last node in the map chart. }\end{array}$ & $\begin{array}{l}\text { The mind map chart should have } \\
\text { maximally } 7 \text { sub nodes in one context } \\
\text { edge. If the distance from the furthest } \\
\text { node is larger }>7 \text {, the map is non- } \\
\text { effective. If final number is bigger than } 1 \text {, } \\
\text { the effectiveness is low. }\end{array}$ \\
\hline Number of Redundancy & $\mathrm{nr}=\mathrm{SUM}$ (redundancies) & $\begin{array}{l}\text { In the mind map, redundancies can exist. } \\
\text { A redundancy can be useful sometimes } \\
\text { (the same word can has different context). } \\
\text { This metric shows the total number of } \\
\text { redundancies in the map. }\end{array}$ \\
\hline Redundancy ratio & $\begin{array}{c}\mathrm{rr}=(\text { number of redundancy }) /(\text { number of } \\
\text { nodes })\end{array}$ & $\begin{array}{l}\text { This metrics shows the relative share of } \\
\text { redundant nodes in the map. This measure } \\
\text { is not useful for small mind map. It } \\
\text { typically smaller then } 1 .\end{array}$ \\
\hline
\end{tabular}

Tab. 1: Measures of mind map effectiveness. Source: (Authors)

\subsubsection{Node points}

This measure is designed to recognize unclear nodes within a mind map, and consequently restructure the map, in order to eliminate these weak points. When node has more than 7 direct descendants, it can be generally deemed too complicated. To identify such nodes in a deterministic way, we design a node point measure, which has a resulting value in range $<0,1>$. The first figure demonstrates a map, which is properly designed from the clarity point of view. 


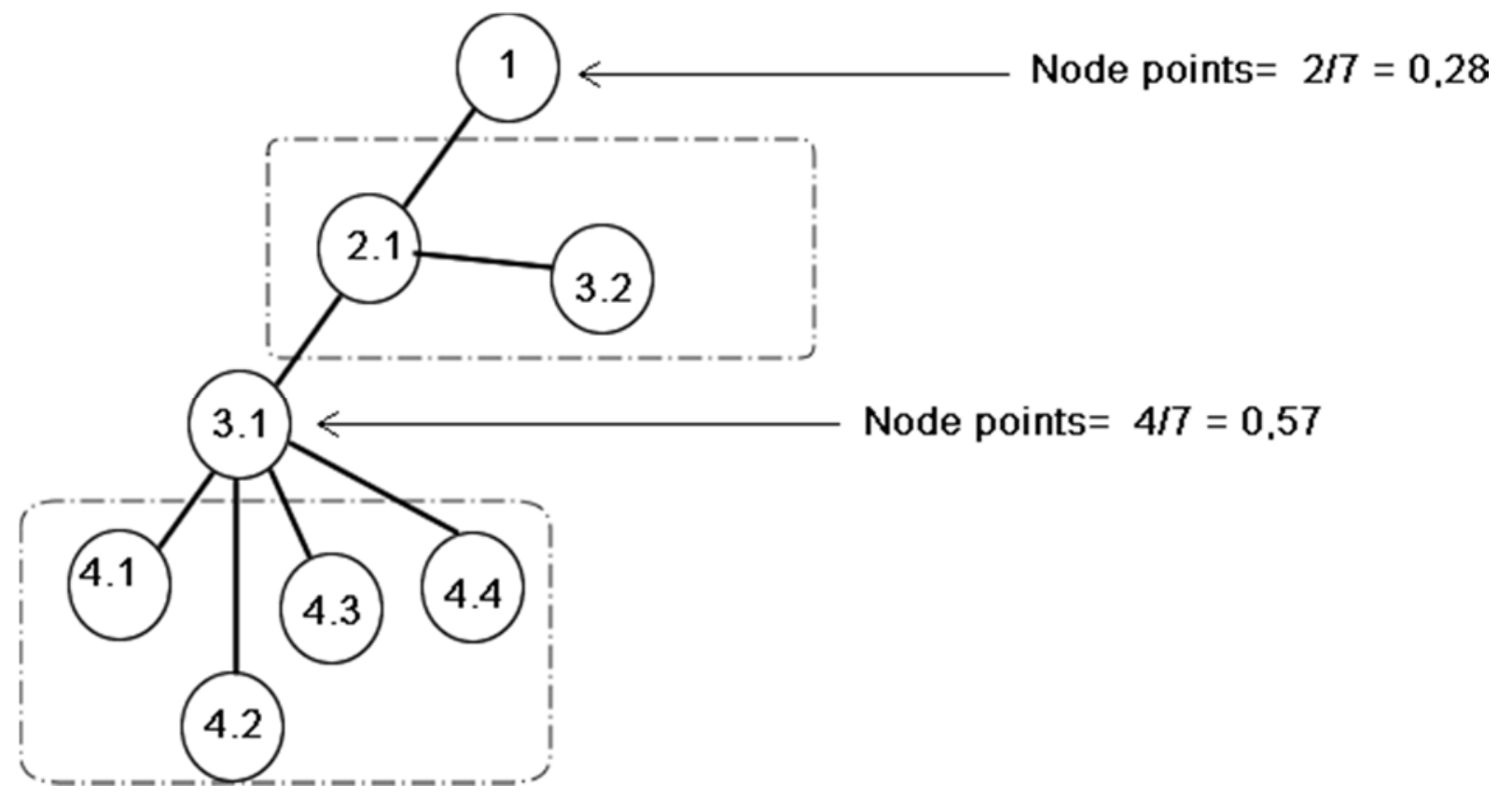

Figure 1: A well-arranged mind map

The second figure in direct comparison shows a subsection of a map with excessive number of sub-concepts, which we consider unclear

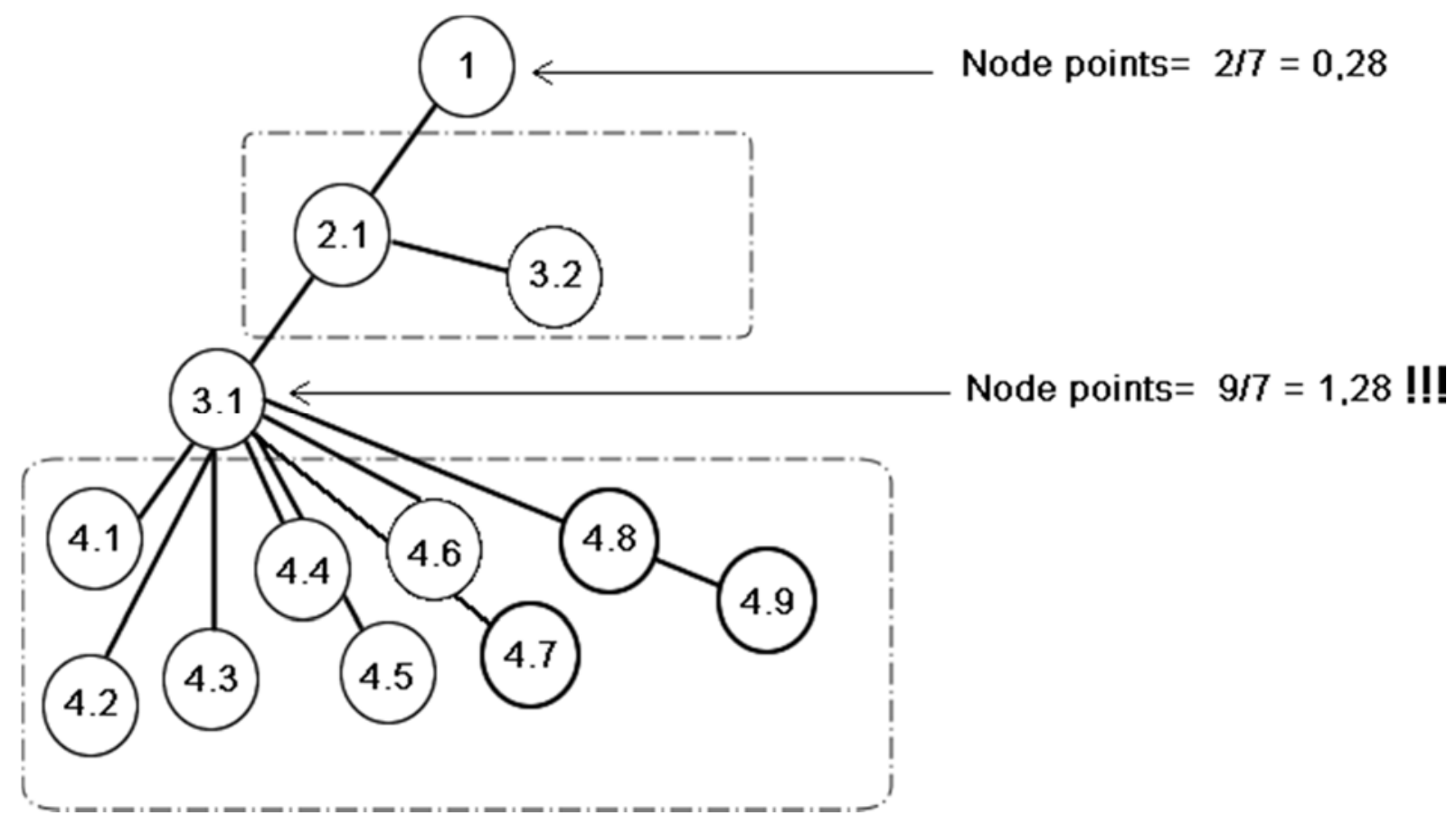

Figure 2: A map with excessive number of child nodes. Source: (Authors)

\subsubsection{Root wide points}

Another problem related to the clarity is the depth of map tree. Every thought in a mind map is separated into individual parts - knowledge. The deeper the node is in a map, the less accessible it is for a user. Therefore, the knowledge stored in close to the central idea is very general. The 
deeper one gets in the map, the more specific knowledge is stored in it. However, the depth of a branch should still be limited. At the current research stage (to keep the rule of seven), we suggest to keep the length of each branch below 7 . When the value of this metric is greater than one, a map designer can most likely transform the map in a way, which increases its simplicity.

The transformation of a map to a clearer form is presented in the following figure:

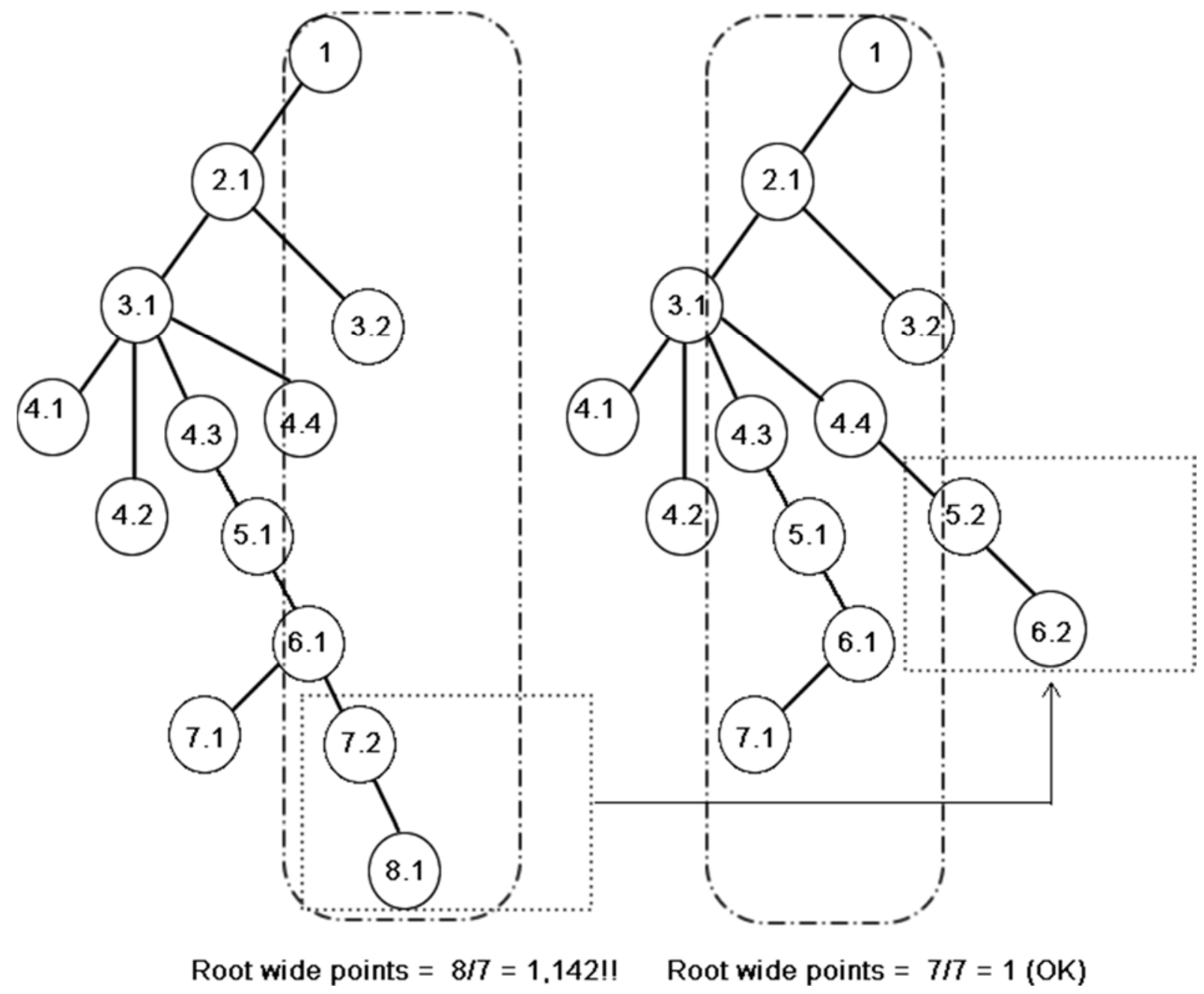

Figure 3: Mind map branch modification based on the RWS metric. Source: (Authors)

\subsubsection{Number of redundancy}

A map can contain various words that share the same context. We have empirically verified such situation regularly occurs in mind maps. Such situation can lead to cyclic behaviour of mind maps. If a descendant node links directly to its parent concept, the content redundancy has been detected.

Patter: Mammals - Cow - Calf - Milk - Mammals

Mind map is in fact a tree; a cyclic relationship among nodes is thus highly undesirable (if it existed, a map could not be a tree). A node can be assessed as redundant based on the occurrence of same words in keywords, or based on the context. A metric called redundancy number is defined based on this assumption. Our empirical research suggests that this measure changes in 
relationship with the problem domain and its purpose. If the mind map should be helpful for classification (description of cultural plants or weeds), the context redundancy is not desirable; this metric should thus be subject of minimization criterion, and approach to zero. In case the map is designed for time management, or meeting scheduling, the context redundancy can be much higher.

Context is very difficult to grasp automatically with software. Therefore, we propose to calculate this measure based on the same words within the map nodes. The absolute precision of this measure is obviously limited; however, it is very reasonable to present the map designer with potential sources of problem. The big amount of redundant words will certainly reduce the clarity of resulting map. If these are eliminated, the map can become more effective.

\subsubsection{Redundancy ratio}

There exists a relationship between the number of identical words in a map and the number of nodes. The larger the map, the smaller the share of redundant words should be. This measure is context dependant. Nevertheless, mind maps' designers can use this information to detect potential points of ineffectiveness. In case the redundancy ratio is greater than 0.5 for a map with more than 20 nodes, it can be concluded such a map is potentially redundant; the knowledge contained within its structure is not very likely well structured. The manual map verification may conclude this is not the case, because of the context of potentially redundant keywords is different; however, such approach is still useful in ensuring the quality of resulting study materials. 


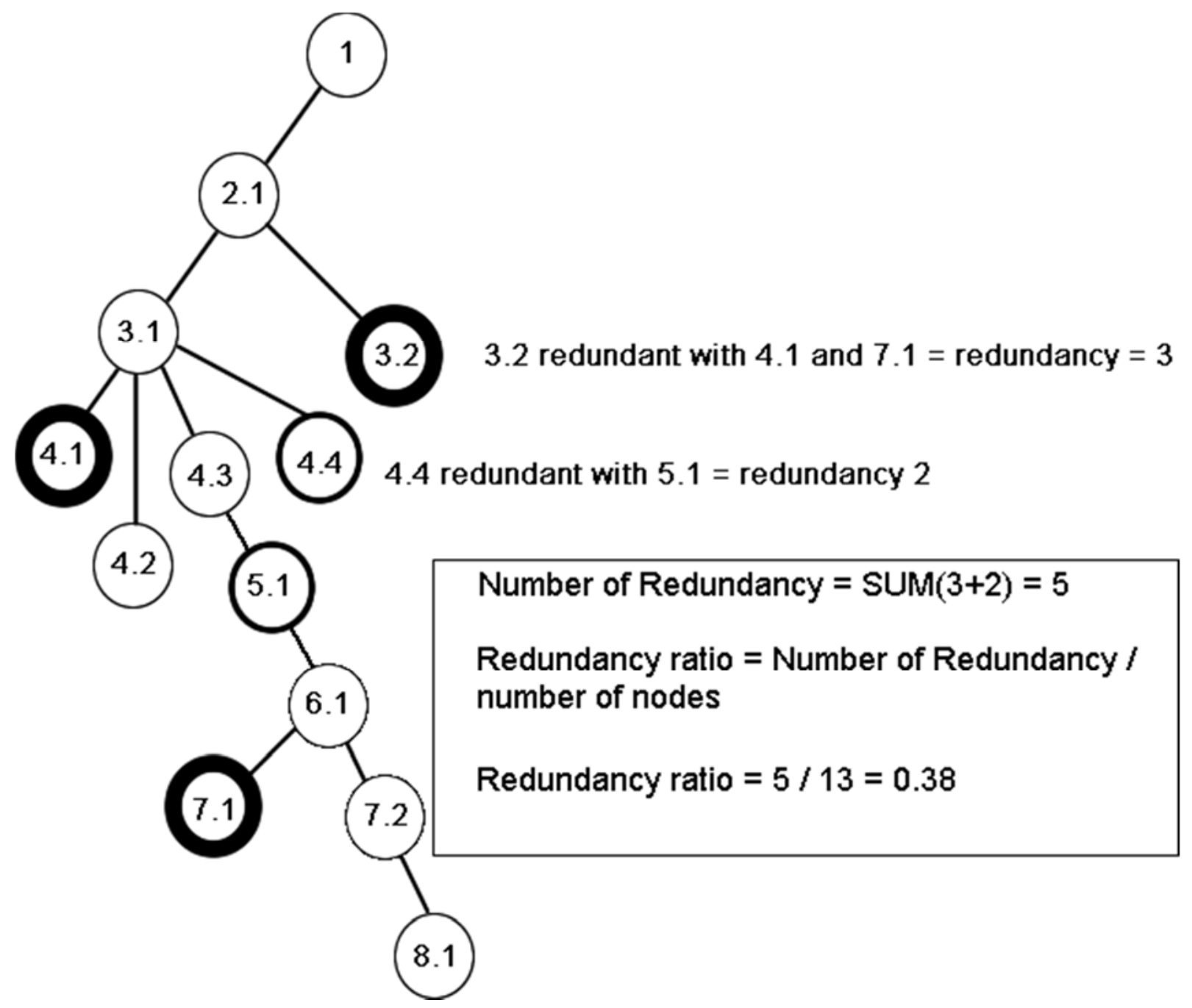

Figure 4: Calculation of mind map redundancy ratio. Source: (Authors)

\subsection{Using the effective mind maps for creating the study materials}

Our research team has proven the students achieve better results when using the materials structured as Effective Mind Maps. This approach also supports making of better links among the study disciplines and build upon the prior studied subjects.

The most significant advantages of Effective Mind Maps are:

- Clear structure

- Illustrative character

- Attractiveness

With the help of Effective Mind Maps, it is possible to illustrate the context of the issue and the relationship between the individual concepts clearly, which is otherwise very difficult to achieve with the textual materials only.

- Creating an educational text using the Effective Mind Maps

- Create an entry guide-post to the entire study material

- Formulate each chapter with a set of keywords 
- Use images instead of text if appropriate

- Use links to audio and video records

Our approach proposes the creation of study materials using a collection of interconnected mind maps. The main entry point in creating a textbook is an interactive content outline, or represented as a core mind map, or a signpost, which provides a link to the entire electronic textbook or lecture notes. By clicking on individual nodes of the map, students can get from the general topic to the specific chapter, issue, and definition. Each paragraph or a contiguous block of information (e.g. Definition or axiom) is described by appropriate keyword.

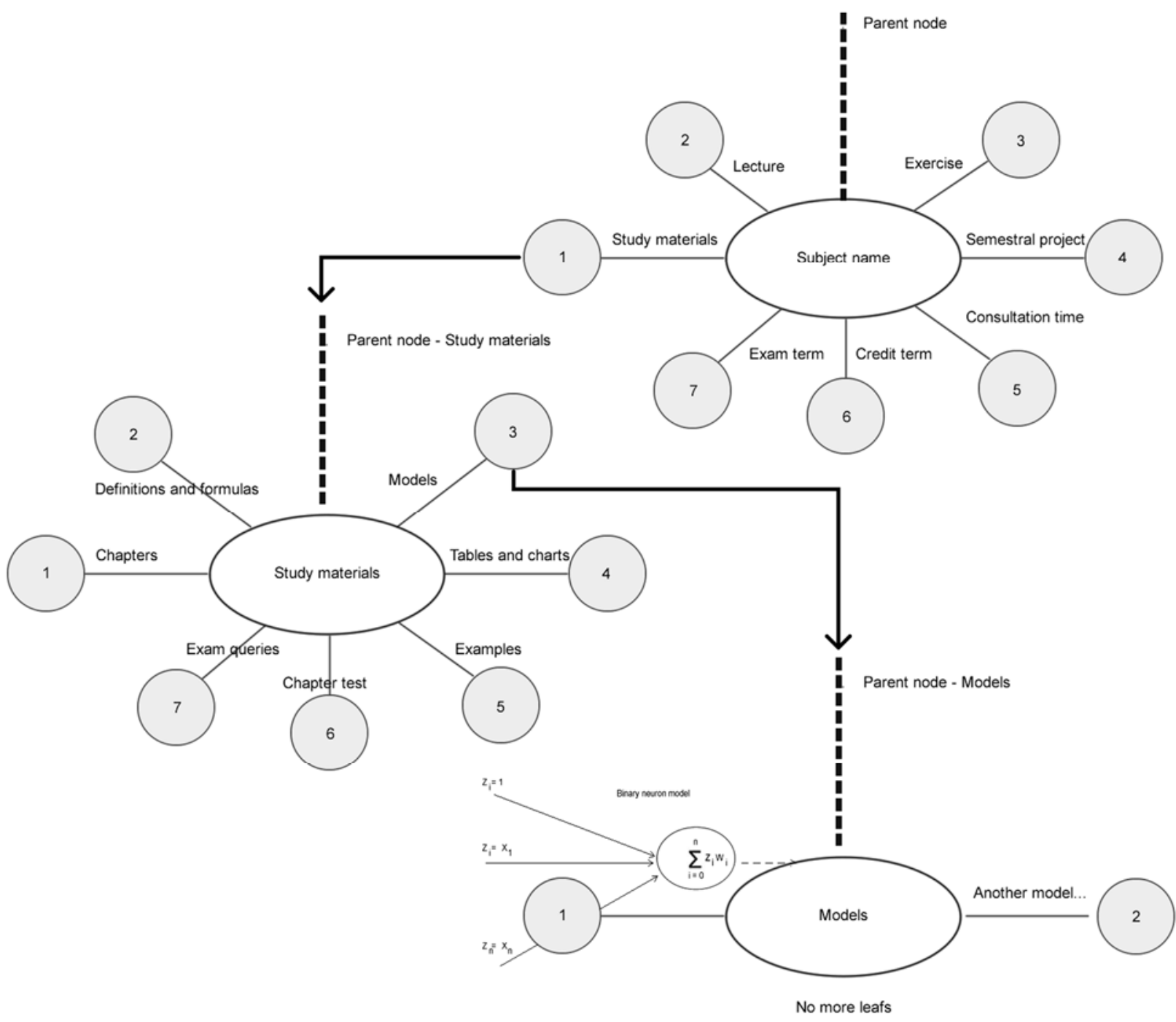

Figure 5: The basic structure of the e-learning course following the rules of Effective Mind Maps. Source: (Authors)

\subsection{Software useful for creating an educational text}

The vital tool for creating the e-learning materials is software. There are plenty of solutions available, but we have positive experience with the Xmind and FreeMind. For creating the study material in the way described above, the iMindMap has also been found especially helpful because of the possibility to link each node with a note. FreeMind on the other hand supports the export to the Flash and moving between individual maps. The second mentioned is also a freeware, which is a factor to be reckoned with. 


\section{Conclusion}

We have introduced the framework for designing the e-learning materials using the Effective Mind Maps. It is not possible to conclude flatly that the proposed mind maps can be used to represent all the possible cases, which can be encountered in education and life. This tool is not suitable for representing problems related to genealogy, such as family trees. Descriptive problems also often require nesting depth greater than 7 (such as a key to classify a weed based on the characteristics of its shape, habit, and location). However, it is a very useful tool for creating online educational courses, where clarity and pragmatism is very important.

By following a set of simple techniques introduced above, the redundancy of the study materials we can be reduced and thus their effectiveness improved. The authors have successfully used the mind maps designed in such a way in creating the context of an e-learning course using the platform moodle.czu.cz. It has been proven the effective mind maps included in this course have helped the student to reach better exam results.

\section{Acknowledgement}

This paper was supported by the grant project IGA 20131029 "The methodical framework for knowledge acquiring in agriculture“.

\section{References}

Budd, J.W. (2004). Mind Maps as Classroom Exercise. Journal of Economic Education, 35(1), 35-46. DOI: 10.3200/JECE.35.1.35-46

Buzan, T. (2005). How to Mind Map. Beijing: Foreign Language Teaching and Research Press.

Buzan, T., Griffiths, C. (2011). Myšlenkové mapy v byznysu. Brno: Computer press.

Chien,L., Buehrer, D., 2008. Using a Typed Mind Map as Knowledge Representation in a TDD DICE System, 30th International Conference on Information Technology Interfaces, Cavat/Dubrovnik, Croatia

Černý, M., (2014a, February 16). How to combine mind maps with programing?. http://www.myslenkovemapy.cz/myslenkove-mapy/byznys/jak-spojit-myslenkove-mapy-a-programovani/

Černý, M., (2014b, February 17). Mind Map Memo: a tool for unassuming. http://www.myslenkovemapy.cz/myslenkove-mapy/tvorba-myslenkovych-map/mind-map-memo-nastroj-pro-nenarocne/

Grabowik, C., Knosala, R. (2003). The method of knowledge representation for a CAPP system. Journal of Materials Processing Technology, 133(1-2), 90-98.

Jamieson, P. (2012). Using modern graph analysis techniques on mind maps to help quantify learning. In Frontiers in Education Conference (FIE). DOI: 10.1109/FIE.2012.6462222.

Mei, L., Yang, K., Chen, H. (2010). Using Mind Maps as a Strategy for Vocabulary Acquisition in Chinese Universities. In International Conference on Computational Intelligence and Software Engineering (CiSE). DOI: 10.1109/CISE.2010.5677128.

Polivaev, D. (2008). FreeMind - free mind mapping software, FreeMind Official Homepage \& Wiki. Retrieved from http://freemind.sourceforge.net/wiki/index.php/Main_Page

Wagner, J. (2014, December 16) Nebojme se e-learningu. Retrieved from http://www.ceskaskola.cz/2004/06/janwagner-nebojme-se-e-learningu.html

Zhang, Y., Xiao, S., Yang, X., Ding, L. (2010). Mind Mapping Based Human Memory Management System. In International Conference on Computational Intelligence and Software Engineering (CiSE). DOI: 10.1109/CISE.2010.5676752.

Zounek, J. (2009). E-learning - jedna z podob učení v moderní společnosti. Brno: Masarykova univerzita. 